\title{
The Rhetoric of Science Meets the Science of Rhetoric
}

\author{
Randy Allen Harris \\ Department of English, University of Waterloo \\ Waterloo, ON Canada
}

Poroi 9,1 (April 2013)

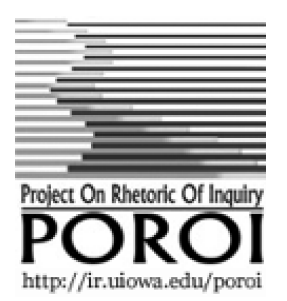

Yes. I know. You've heard this before.

Every generation or two, some rhetorician wants to put on a lab coat and declare rhetoric a science. Herb Simons (1978) wrote a paper with a similar title at the very beginnings of the rhetoric of science movement, and Alan Gross (1993) has weighed in as well. A hundred years before them, David J. Hill wrote a textbook entitled The Science of Rhetoric: An Introduction to the Laws of Effective Discourse, suggesting that suasion worked pretty much like gravity. We can go further back. A nineteenth century biographer of Aristotle, Anonymous, dates "the science of rhetoric" to our very disciplinary origins, to Aristotle, who founded the field on "scientific principles," in striking contrast to the loose unmethodical approach of Isocrates, who "professed to teach [rhetoric] by mere practice in the schools, as boxing and fencing might be learnt" (“Aristotle," p. 144). We've been down this road before.

But.

Anonymous has a point. Among the many streams in the rhetorical tradition, there are prominent, divergent courses between the impulse to understand persuasion and the impulse to achieve persuasion, and those two motives date to the very first writings in the field. ${ }^{1}$ Aristotle and Isocrates were animated by both impulses, of course. The division is not as clean and absolute as Anonymous would have it, nor as I am adumbrating in these very brief observations. But Anonymous is clearly right that the Aristotelian approach, framed by the man who did so much to anchor the core empirical and formal enterprises that now wear the term science so comfortably-physics, biology, geology-is oriented more fully toward understanding, and, for that reason, has a higher claim on that god-term, science.

Now, we all know that the various and scattered moves to propagate the colligation science of rhetoric have been somewhat less successful

\footnotetext{
${ }^{1}$ I certainly don't mean by this that the two enterprises shaped by these impulses-rhetoric docens and rhetoric utens-do not mutually inform each other, only that they may be, and frequently are, pursued independently (or, more accurately, since it is impossible that the one does not implicate the other, that they are pursued with one heavily dominant, the other heavily subordinate).
} 
than for the reverse colligation, rhetoric of science. There is no ASTR, no Association for the Science and Technology of Rhetoric. What's different now? What snake oil is Harris selling?

The cognitive sciences.

What I propose, in this brief position paper, is to (1) warrant the subfield, cognitive rhetoric, and (2) connect this sub-field to rhetoric of science, while simultaneously (3) reconfiguring Kenneth Burke, and (4) riding shamelessly on the coattails of Jeanne Fahnestock.

Cognitive rhetoric, in its fundaments, begins with Kenneth Burke, though its presence has clearly been felt at least as far back as Hesiod, whose princes made sorrows disappear with their sweet flowing speech; or as Gorgias, who likened the psychological results of suasive tools to the physiological effect of the pharmacopoeia; or as Plato, who complained that certain forms of speech appealed to the mind as tasty food to the tongue. Physiology is never far away when these aspects of languageaffect, delight, enchantment-are commended or condemned. Burke, who shared the concerns of the ancients for the medicinal as well as the toxic aspects of rhetoric, articulated a program resting on the axiom that the form signification assumes profoundly affects the way human organisms respond to it.

In a language of "human appetites" and aesthetic "desires" (1931, pp. 34-35), Burke charted the semiotic factors that shape the response of humans to language and symbol systems generally. ${ }^{2} \mathrm{He}$ was uncomfortable with absolutes, and the terministic apparatus of cognitive science post-dates his work in these areas by decades, but he makes the point penetratingly in this well-travelled passage from Grammar of Motives that there is something "universal" about certain structures of signification:

\footnotetext{
${ }^{2}$ If we were to adopt a fully Burkean terminology for this project, we would have to call it "cognitive grammar," since he locates this area of his research in "formal considerations logically prior to both the rhetorical and the psychological" (1969 [1945], p. xviii). But, (1) cognitive grammar is already taken, by an intriguingly overlapping but very differently oriented framework, in linguistics; and (2) Burke's use of rhetoric (as revealed in all of his work, but most expressly identified in Rhetoric of motives) is utterly dependent on the "universal resources of verbal placement" (1969 [1950], p. 22) - that is, on style-which he identifies with grammar. His relevant work is also chronologically prior to the cognitive revolution. The later stages of Burke's career overlapped with that (still ongoing) revolution, but the positions in his work I am drawing on pre-date it by several decades. In that period, his direct contact with psychology (virtually everyone's direct contact with psychology) engaged either psychoanalysis or behaviorism. The first Burke found amenable with certain currents of motivation, but did not link them to his "grammar." The second he never tired of attacking (an attitude adopted by the first wave of cognitivists-George Miller, Jerome Bruner, Noam Chomsky). Like those early cognitivists, he regarded behaviorism as an exclusively zoological enterprise, whose results had nothing of consequence to say about the human mind. For Burke (in a position advocated by the cognitivists, in apparent ignorance of Burke's arguments), the unbreachable divide was the human use of symbols (see especially, 1966, p. 3ff).
} 
[Certain patterns of signification invite our participation because they] awaken an attitude of collaborative expectancy in us. For instance, imagine a passage built about a set of oppositions ("we do this, but they on the other hand do that; we stay here; but they go there; we look up, but they look down," etc.) Once you grasp the trend of the form, it invites participation regardless of the subject matter. Formally, you will find yourself swinging along with the succession of antitheses, even though you may not agree with the proposition that is being presented in this form. ... [A] yielding to the form prepares for assent to the matter identified with it. Thus, you are drawn to the form, not in your capacity as a partisan, but because of some "universal" appeal in it. (Burke, 1969 [1945], p. 58)

Burke shows very clearly here how swinging along with the form provides a rhythm that can easily get us swinging along with the proposition. It awakens an attitude of collaboration with the rhetor, very much like a dance, in which we step and sway as the rhetor directs us; collaborating, but asymmetrically: led. Burke's concern, very much like Plato's, is that being directed in a series of movements by the "form" will get us moving with the "matter" as well. The collaboration is really a highly inequitable faux collaboration; puppetry might make a better analogy than dance.

The question Burke opens up here is: how do minds function when they are exposed to the traditional furniture of rhetoric-patterns of concepts and patterns of sounds; in a word, style. What are the sources of the "universal" appeal that Burke charts? What is it about the human organism that resonates to successions and to oppositions, and even more fully to successions of oppositions? And to the other collective factors in this passage, left unmentioned by Burke? Let's take the charting a bit further:

- we do this, but they on the other hand do that;

- we stay here; but they go there;

- we look up, but they look down;

It is quickly clear that succession and opposition are not the only "universal resources of verbal placement" (Burke, 1969 [1950], p. 22) the passage deploys. Parallelism is also at work here. Both the succession and the opposition, which mutually reinforce each other, are further bolstered by synchronized rhythmic repetitions. Brute lexical repetition adds another factor to the rhetorical (or "grammatical") pull of the passage, with the three we's, the three they's, pivoted by the three but's, and joined by two do's, two look's. Phonological repetition lends a hand, partially entailed by the lexical repetitions (same words, same sounds), partially augmented by the number of vowels and consonants that make repeat appearances in different words. There are also conceptual repetitions galore, in the precisely repeated words themselves (same words, same concepts), but also in the pairs of antonyms, each of which references the same semantic domain-down repeats vertical direction, referenced by up; there repeats spatial proximity to the rhetor, referenced by here; that repeats relative-valence-to-rhetor, referenced by this. Formal location is also important to the passage, as the repetitions, both syntactically and 
lexically, concentrate in certain places, mostly beginnings (of phrases or words), but also middles. Equally crucial, as well, is that all of these verbal resources are (temporally and/or spatially) proximal to one another. The fact that the oppositions are cheek-by-jowl increases their salience (and, of course, the same is true for the repetitions).

Compare, for instance, this succession of antithetical propositions:

- we do this, and we stay here;

- but they go there and we look up;

- they on the other hand do that, and they look down.

If not for the counter-example of an infinite number of PowerPoint presentations, one would almost be tempted to abandon bullets here; the phrasing has fallen so dramatically out of sync. This slight rearrangement causes so much verbal dissonance that these pairings do not easily belong side-by-side. We still have "a set of oppositions" here, in Burke's description. The specific oppositional pairings, along with the overall thematic we/they division, can certainly be reconstructed, and form inevitably plays a substantial role in pointing the way to such a reconstruction (the similarity of the deictics, and of the prepositions, and the identity of full-court repetitions, all exert strong forces of adhesion here). But there is much less of the waltz in this second version, much more of something like hide-and-seek; less collaboration, more wrangle. (Correspondingly, Burke might point out, there is less danger of being pushed and pulled around the rhetor's dance floor.)

The factors at work in Burke's passage-repetition, contrast, parallelism (a particular order of repetition), position, and proximity (along with a few others, like symmetry, similarity, and transitivity)-are the staples of rhetorical style. The instances of these factors in Burke's little example all have venerable names: antithesis, isocolon, assonance, alliteration, epanaphora, mesodiplosis . . . Burke's collaborative expectancy, in short, is built out of rhetorical figures.

Here is my cognitive claim, then: rhetorical figures operate in the grooves of the mind. But not only figures: topoi (which Fahnestock has shown to bear systematic correspondences to figures), narrative (which is a kind of 'succession' in Burke's terms, and which allows for a wide array plot "curves" through interaction with other factors, like opposition and progression), syllogisms (which are inconceivable without semantic repetition and transitivity) - in sum, the whole assortment of verbal and semiotic resources involved in human "efforts to discover and share warrantable assent” (Booth, 1971, p. 106). Rhetoric. Is. Cognitive.

What is new here, you ask? Burke was, after all, working on these ideas in the twenties and thirties. But Burke was working with a wholly untethered notion of universality. That's one of the reasons he puts universal in safety-quotes in the passage above. In the last five decades, however, the cognitive sciences have developed a variety of frameworks for investigating the shared structures of brain and of mind that define the human organism. Unsurprisingly, there are compelling overlaps among these frameworks and Burkean formalism. 
The most celebrated of these overlaps (including in much philosophy of science) is similarity; or, as it is so widely known in such studies, metaphor. But all four of the "master tropes" in one of Burke's set pieces (1969 [1941], pp. 503-517), have received cognitive attention, chiefly among linguists. Schemes, with even more striking cognitive implications, have gone unnoticed, and present very rich research possibilities. We know, for instance, that the brain operates at the most elemental level on repeated neural firings, in repetitive constellations. Repetition is one of the most pervasive aspects of schemes (and some tropes). We know that edges are important perceptually, to the cognitive systems of vision and audition especially. Visual boundaries between objects and non-objects and auditory boundaries between notes and between speech phones are zones of special salience. Schemic activity, as we have seen in Burke's we/they passage, clusters at the boundaries of phrases (epanaphora and epistrophe, most obviously, but also mesodiplosis, which regularly marks the junctions between phrases) and words (alliteration is at the beginnings of words, rhyme usually at the end); theories of arrangement stress beginnings and ends of speeches, and transitions between sections.

The research potentials in cognitive rhetoric are very broad. Crosscultural rhetoric, for instance, can be central in exploring these "universal resources," uncovering the different instantiations the factors play in the aesthetic and suasive regimes of different languages and cultures. Developmental rhetoric-as far as I know, a wholly imaginary (sub-) discipline-is tremendously ripe. Anybody with more than ten seconds exposure to children knows that they thrive on repetition. But how does it manifest? When does analogic reasoning appear? Is personification linked to Theory of Mind? Apostrophe? Irony? Degenerative rhetoricalso currently a figment of my imagination-is equally ripe, and perhaps more urgent. Do repetitions, schemic placements, and rhythmic intonations aid dementia patients in understanding or retention? Do Broca's syndrome patients retain the ability to recognize metaphors? Do Wernicke's syndrome patients lose it?

Where is science in all of this? In part, it is embedded in the methodologies necessary to explore some aspects of cognitive rhetoric. Hence, the science of rhetoric, which can help ensure, as Gross observed in 1993, that the results of our field begin to add up, rather than just pile up (p. 29). (It may also be worth pointing out at this node in the discussion that incorporating scientific methods, generating scientifically ratified results, publishing in scientifically sanctioned journals, would not hurt the ethotic appeals of rhetoricians seeking to work with scientists.)

Where, then, is the rhetoric of science? What is the relevance of cognition to the rhetorical exploration of science? We need look no further than our esteemed colleague, Jeanne Fahnestock, whose Rhetorical Figures in Scientific Argumentation and related publications (1999; 2003, 2004a,b, as a sampling), elaborates a masterful program for the investigation of scientific argumentation in figural terms. After Fahnestock published the book, I wrote a mostly appreciative review. The book is magnificent. But I had a petty and ill-founded complaint to make as well. I quote myself (I could paraphrase, but quotation is better for my citation indices): 
[... much laudation ...] Professor Fahnestock does not, however, walk on water. This book has one serious shortcoming, to my eyes, which prevents it from being truly groundbreaking. Aside from metaphor, figuration has long been little more than an embarrassing reminder of the shallowest notions of style for almost everybody, including most rhetoricians. But (aside from the appreciation for metaphor) this is utterly backwards. Figuration runs as deep as it is possible to run. Language cannot but be figured; it flows in what Edward Sapir figured as "well-worn grooves of expression" (1921, p. 89). These grooves can be optimized to aesthetic or rhetorical ends (or, often, both)-which is where formal theories of figuration come in-but there are no other channels. Figures are the very stuff of language, the bones and muscles, nerves and skin, blood and guts. They are the very opposite of, in Plato's famous assault, the "colours, and enamels, and garments" (Gorgias, $465^{3}$ ) daubed on, and painted on, and draped over an otherwise pallid, and virtuous, and naked language. Fahnestock sees the linguistic ineluctability of figures truly and argues it clearly. She vitiates all approaches to figuration in which "one begins with a plain message and then adds secondary features that make it more memorable or convincing than it would be without them" (p. 21). But-sorry for taking so long; here is my complaint-she unaccountably pulls up halt before the inevitable next step. Figures are the stuff of language. Language is profoundly cognitive. Throw modus ponens into the breach and you've got: figuration is cognitive. (Harris, 1999, p. 92)

I ended the review with the most reprehensible of my complaints, "Fahnestock missed the boat" (p. 103). It was certainly not her job, especially in a book that does so much else, so brilliantly, to integrate that work with the voluminous multidisciplinary research that constitutes cognitive science. But she was gracious enough to respond not as the remark deserved. She did something quite wonderful.

She sifted through a great deal of that voluminous research (2005), identifying several important points of contact, and sketching a research approach of reciprocal support. She proposes, first, that cognitive science needs to be informed by a figuratively rich "rhetorical theory of language" (p. 174) in place of the arhetorical generative theories that have been the staple of cognitive science for most of its existence. She is exactly right in this. Cognitive science does need rhetoric. ${ }^{4}$ And she suggests, second, that rhetoricians need to be open "to potential scientific grounding," reminding us that rhetoric always, in the end, "come[s] down to human brains acting on human brains" (p. 175).

\footnotetext{
3 See www.mylibrarybook.com/books/831/Plato/Gorgias-16.html.

4 In fact, there is a growing opening in exactly this area, in the linguistic framework I invoked above, Cognitive Linguistics. It founds itself on Lakoff and Johnson's (1980) Metaphors We Live By, extending their approach to a few select tropes (see, for instance, the journal, Cognitive Linguistics, published by Mouton de Gruyter). What this line of research shows is how much they could benefit from collaborating with rhetoricians.
} 
What makes this cognitive grounding especially crucial for the rhetoric of science is exactly what makes the rhetoric of science the crucial occupation it is in the first place. Science is where human brains (and their associated perceptual and mechanical systems) make the most robust, most hopeful, most dangerous constellations of knowledge that human brains can make. Science is what calls the tune for most of our dances.

The position that the form of signification profoundly affects the response of human organisms is well known in the history and philosophy of science, perhaps most closely associated with Gerald Holton's work on themata (1973). Signification that comes in simpler packages, or comes with greater implications, or comes with closer integration to already accepted significations, is more attractive to those human organisms we call scientists. They are more likely to call it true, to add it to their repertoires, to deploy it in the making of artificial organs and renewable energy devices and environmental poisons and weapons of mass destruction. The more we understand the elemental components of that knowledge (deeper and more pervasive than Holton's themata), the more we can chart its reliance on the kind of wetware that defines us as human organisms, the better equipped we will be to influence and educate the culture that defines us as social, political, historical, organisms.

I am not claiming there are laws of suasion, as Hill did, in my appeal to a science of rhetoric, only that cognitive science has immense promise as a pillar in a new twenty-first century rhetoric docens, for understanding science as an epistemological extension of human organisms.

\section{Afterword: Displacement, Condensation, and Response}

I did not read this paper at the ARST pre-conference. Rather, I sketched out my ideas along the following lines, starting with a disavowal of my title.

I deliberately chose a somewhat asinine title to get people talking. I have no pretensions for, or real interest in, charting out a program of study that brings the machinery of science to rhetoric in any pervasive or systemic way. In any case, it's not the overlaps or intersections with science that makes these ideas compelling to me. It's their deep explanatory capacity.

So, stripping that away, what are my claims?

I claim that there is a range of cognitive affinities that underlie the aesthetic and suasive characteristics of semiosis. These affinities include similarity, contrast, association, scale (increase and decrease), edgedetection, parallelism, symmetry, and repetition. They should sound familiar. They correlate with topoi. They undergird figures. They comprise style. They shape thought and belief, learning and memory and argumentation. 
At its most powerful, discourse that activates one or more of these affinities has a kind of deja-vu feel to it that Burke calls "collaborative expectancy." The structure and trajectory of some configurations are so familiar that you know where they are going before they get there. You get there first, and impatiently wait for the rhetor. It's your discourse. The rhetor is only speaking it. An example Burke cites from the rhetorical climate of 1948 is:

Who controls Berlin, controls Germany; who controls Germany controls Europe; who controls Europe controls the world.

"As a proposition, it may or may not be true," Burke comments. "But regardless of [our] doubts about it as a proposition, by the time [we] arrive at the second of its three stages, [we] feel how it is destined to develop and on the level of purely formal assent [we] ... collaborate to round out its symmetry by spontaneously willing its completion and perfection as an utterance" (Burke, 1969 [1945], pp. 57-58).

What gives it this character; or, rather, what gives us this character, when we hear such constructions? The shape of our minds; the affinities we have for, in this case, repetition (who controls, controls, Berlin) edge detection (the repetitions occur at phrase boundaries), parallelism (syntactic and prosodic repetitions), and scale (the semantic scope of the direct objects increases).

Now, the reason we bring rhetorical theory and criticism to science is because we recognize there is something important and powerful about scientific discourse. When we can bring our rhetorical approaches to science, we bring them to the most potent and ubiquitous discourse of the age.

Let's take a quick look at how pervasive these cognitive affinities are, by way of two symbols in the central formula of Gregor Mendel's (1866) "Experiments on Plant Hybrids."

$$
\frac{A}{A}+\frac{A}{a}+\frac{a}{A}+\frac{a}{a}
$$

Gregor Mendel's formula for the distribution of dominant (A) and recessive (a) character traits. From Mendel (1966 [1866], 30).

Figure 1

Repetition is present in abundance, most significantly in the two variables $(A, a)$, which illustrates how fundamental it is to mathematical and logical reasoning. If one wants to reference and manipulate the relations among identical concepts or multiple iterations of identical concepts, 'lexical' repition is invetiable; figuratively, this is ploche.

Similarity is also prominent $(A \& a)$. When variation along a controlled dimension is important, similarity of symbol or structure 
evokes that variation; figures such as polyptoton and homeoteleuton are operate on theme-and-variation similarity. Another aspect of similarity (this one less prevalent in mathematics, more specific to Mendel's argument) is in the relative upper-case/lower-case correlation with the 'magnitude' of the effect. The upper-case letter signals the dominant trait, the lower case, recessive; the figural corollary is onomatopoeia.

Opposition is crucial to Mendel's formula ( $A \& a$ ), in slightly more subtle ways, since the dominant and recessive traits are necessarily in the same genetic (or, better, semantic) 'space.' The expression of one trait is exclusive to the expression of the other; figuratively, we have antithesis.

Symmetry plays perhaps the definitive role in the formula, because it demonstrates the experimental design. Mendel is showing, with the inverted parallelism of the second and third elements $(A / a$ and $a / A)$, that all possible combinations of dominant and recessive character traits from the two sources (seed and pollen) have been included; figuratively, this is antimetabole. 5

Mendel's formula, and the paper that frames it, was not immediately successful. But it became so compelling as to define an entirely new branch of science fifty years hence. It is a classic example of suasion deferred. By looking at the formula in light of cognitive affinities, we can see more clearly the reasoning and invention in Mendel's experimental design.

The "Horizons of Possibility" panel, and the entire ARST preconference, was helpful to me in sharpening my thinking about many of these issues, and the suite of position papers and responses will continue to be an important resource for me in future work. The caliber of work in this field generally, and by the particular players at this preconference, always impresses me. I am especially thankful to Leah Ceccarelli and Carl Herndl for their vision of other possibilities in rhetoric of science and technology, and for sharing the panel with me; and to John Angus Campbell, Carolyn R. Miller, and Lynda Walsh for the helpful scrutiny they turned on my arguments specifically. I do want to quell the fears of Walsh and Miller somewhat, however.

Of all the people in the world I didn't think Plato would have to fear, Carolyn R. Miller would have been at the top of my list, but here she is in her response paper: "the ultimate promise of cognitive rhetoric is that we can learn to use form to control humans. This has been the rhetorical dream" (Miller, this issue). Er, no. This has been the rhetorical nightmare. The ultimate promise of propaganda, and in its scientistic version, neuromarketing, is to use form to control humans. The ultimate promise of rhetoric is to inoculate humans against such control. Walsh offers a similar picture of my approach, when she writes, "Let's say we

5 This survey of affinities in Mendel's formula are from an article currently in review, "Figural Logic in Gregor Mendel's 'Experiments on Plant Hybrids.” As the title suggests, the paper is deeply influenced by Jeanne Fahnestock's work. James Wynn's research on Mendel $(2007,2012)$ was also very important to my arguments in that paper. 
operationalized it so that we could predict the positions of stakeholder groups and the outcome of public science policy debates with 95\% accuracy" (Walsh, this issue).

The point of researching the cognitive underpinnings from a rhetorical perspective, especially one so deeply rooted in Kenneth Burke, is not to predict and manipulate, but to understand, to align that understanding with the ethical awareness Miller calls for, and to use that alignment in ways that improve society, prominently including science.

Look, Carolyn, Linda, and anyone else who shares these concerns: in labs all over the world there are subjects strapped into fMRI scanners right now by marketing people and political strategists. Lies are being tested. Cortical real estate is lighting up. We won't stop the testing by simply declaring all (neuro-)cognitive rhetoric is inherently bad or immoral. Luckily, I'm pretty sure the neuromarketing research is misguided and simplistic. No one even knows what it means for cortical real estate to flicker briefly. But, to the extent that these people do find tools of manipulation based on the structure of the mind and the wiring of the brain, we are the folks who should be able to understand, resist, and counter the strategies they develop. In any case, it would surely "be a mistake," as a recent overview of neuroscience and persuasion in this journal pointed out, "to ignore the materiality of bodies in the constitution of perception” (Gruber, Jack, Keränen, McKenzie, \& Morris, 2011, p. 4).

And, one final note. Miller calls in her response paper for increased attention to digital communicative technologies in rhetoric of science, a call I heartily endorse. Cognitive rhetoric has much to offer in this realm. These technologies reflect the secondary orality that Walter Ong and Marshall McLuhan talked about in their work on the electronic age, to a far greater degree than does television, perhaps even than does radio. Figures are the original technology of distributed cognition. They have such a presence in oral literature, in proverbs, heuristics, and rules of thumb, because they have a cognitive stickiness. Print culture put pressure on overt figuration in many ways, because the page is an external technology of distributed cognition that utilizes visual modes of representation (many of which, as the Gestalt principles demonstrate, reflect the same affinities-repetition, similarity, contrast). With the advent of Twitter, Tumblr, Facebook, and other fragmentary mediawhere science is getting done-they may be coming to fore again. Look, for instance, at how many figures show up in Facebook shares and tweet propagations. 


\section{References}

“Aristotle.” (1848). In H. J. Rose (Ed.), A new general biographical dictionary, volume 2 (pp. 142-153). London, UK: Richard Clay.

Booth, W.C. (1974). Modern dogma and the rhetoric of assent. Chicago, IL: University of Chicago Press.

Burke, K. (1966). Language and symbolic action. Berkeley, CA: University of California Press.

----. (1969 [1945]). The grammar of motives. Berkeley, CA: University of California Press.

----. (1969 [1950]). The rhetoric of motives. Berkeley, CA: University of California Press.

Fahnestock, J. (1999). Rhetorical figures in scientific argumentation. New York: Oxford University Press.

----. (2003). Verbal and visual parallelism. Written Communication, 2O, 123-152.

----. (2004a). Figures of argument. Informal Logic, 24, 115-135.

----. (2004b). Preserving the figure consistency in the presentation of scientific arguments. Written Communication, 21, 6-31.

----. (2005). Rhetoric in the age of cognitive science. In R. Graff (Ed.), The viability of rhetoric (pp. 159-179). Albany, NY: State University of New York Press.

Gross, A.G. (1993). The rhetoric of science and the science of rhetoric. In A. W. Halsall (Ed.), Proceedings of the Canadian Society for the Study of Rhetoric, 4, 1991-92 (pp. 8-35). Ottawa, Canada: La Société.

Gruber, D., Jack, J., Keränen, L., McKenzie, J.M., \& Morris, M. B. (2011). Rhetoric and the neurosciences: Engagement and exploration. Poroi, $7(1)$.

Harris, R. (2001). Review of Fahnestock, 1999. Rhetoric Society Quarterly, 31, 92-104.

Hill, D. J. (1877). The science of rhetoric: An introduction to the laws of effective discourse. New York: Sheldon \& Co.

Holton, G. (1973). Thematic origins of scientific thought: Kepler to Einstein. Cambridge, MA: Harvard University Press.

Lakoff, G., \& Johnson, M. (1980). Metaphors we live by. Chicago, IL: University of Chicago Press.

Mendel, G. (1966 [1866]). Experiments on plant hybrids (E.R. Sherwood, Trans.). In C. Stern \& E.R. Sherwood (Eds.). The origin of genetics: A Mendel sourcebook (pp. 1-48). London, UK: W. H. Freeman. 
Mendel, G. (1866). Versuche über Pflanzen-Hybriden. Verhandlungen des naturforschenden Vereines in Brünn, 4, 3-47. Plato (1871) Gorgias. (B. Jowett, Trans). Accessed April 8, 2013. www.mylibrarybook.com/books/831/Plato/Gorgias-1.html

Simons, H. W. (1978). The rhetoric of science and the science of rhetoric. Western Journal of Speech Communication, 42, 37-43.

Sapir, E. (1921). Language: An introduction to the study of speech. New York: Harcourt, Brace.

Wynn, J. (2007). Alone in the garden: How Gregor Mendel's inattention to audience may have affected the reception of his theory of inheritance in "Experiments in Plant Hybridization." Written Communication, 24, 3-27.

----. (2012). Evolution by the numbers: The origins of mathematical argument in biology. Anderson, SC: Parlor Press. 